\title{
The Flow of Gender Equality Education Practices in China and the Media Bias in the New Era: From the Perspective of Sociology of Knowledge
}

\author{
Tunan Huang ${ }^{1, a, ~}{ }^{*}, \dagger$, Xintong Liu ${ }^{2, b, *, \dagger}$ \\ ${ }^{1}$ School of Humanities, Zhejiang University, Hangzhou, Zhejiang, 310030, China \\ ${ }^{2}$ Faculty of International Media, Communication University of China, Beijing, 100020, China \\ *Corresponding author.Email: ${ }^{*} 3180104974 @ z j u . e d u . c n,{ }^{b} l x t l e e l o o @ c u c . e d u . c n$. \\ ${ }^{\dagger}$ Those authors contributed equally.
}

\begin{abstract}
Achieving gender equality in education is one of the key goals of China's educational modernization and democratization and a fundamental means of achieving gender equality in China. This paper takes a perspective of the sociology of knowledge to reflect on and examine the tradition of gender education in China since the second half of the nineteenth century, analyzing why and how the institutions, ideas and knowledge about gender equality education have been formed and changed, and how they have interacted with different historical traditions and social situations in a subtle and complex way, which is the key to understanding the state of gender equality education today. At the same time, in today's mediated age, the media's all-around penetration of society has naturally given it a broader implicit educational function. In the new environment created by internet technology, the media bias ignored by classical sociology of knowledge has become an important variable in its own right. New technologies and new media platforms also offer new possibilities for stability breakthroughs beyond mainstream education. However, it is important to avoid falling into blind techno-optimism and be wary of alienation and assimilation under the triple logic of capitalism, politics and technology.
\end{abstract}

Keywords: Gender Equality Education, Sociology of Knowledge, Cyberspace.

\section{INTRODUCTION}

As China opened itself up to the outside world, the country has joined the global discourse system. This has led to the introduction of western humanistic and social scientific thought, further popularization and the opening up of mass media and cyberspace. Thus, the discourse of gender in Chinese society was gradually being demystified. This has been accompanied by the popularization of gender theory, the relative improvement in the socio-economic status of Chinese women, as well as the educational and technological empowerment, especially in online media technology. Therefore, more and more people, especially women, were beginning to rethink traditional Chinese gender ideas. Thus, gender equality emerged as a social issue or even a popular social culture in China.

Education, as an important tool for the growth and development of human beings, determines the development process of the progress of civilization in human society, and gender equality education is an important tool for achieving the goal of equal development. Since the second half of the nineteenth century, and especially after the establishment of New China, women's education in China has improved rapidly, and institutional differences have been broken down gradually. However, it has never achieved gender equality beyond figures truly and has not yet fundamentally challenged the persistent gender preference and gender role differentiation in education. The "otherness" of women in education has not yet been effectively improved [1].

In the past two decades, research on gender equality education has received increasing attention and has become more popular, and the gender perspective has been widely used in the field of education. In terms of research paradigms, current research mainly adopts two paradigms: deductive research and inductive research, either using psychological research results as the theoretical basis to analyze the formation and impact of 
biological and psychological differences between men and women to find strategies to cope with them in education $[2,3]$ or using data collection, textual analysis and interviews to investigate and generalize the gender equality situation in education, trying to uncover the various gender issues that exist in our contemporary education sector and to propose corresponding educational reforms concerning these issues [4-6]. However, there is little discussion on how the existing concepts of gender education in China have been constructed, their historical roots and social situations, and the interaction between reality and tradition.

Education has been inextricably linked to society since its inception. The acquisition and transmission of knowledge come from education, and the development of human beings themselves and society depend fundamentally on the level of educational development, and the social conditions of different periods also influence the changes in education [7]. A review of the intellectual and social contexts in the history of modern Chinese educational thought reveals that the emphasis on gender equality was not only a reflection of new ideas and thoughts in the field of education but also closely related to the changes in the mainstream political discourse of society as a whole. Sociology of knowledge is a discipline that studies the relationship between the production and development of knowledge and ideas and society and culture. The realistic factor in the presentation of knowledge is the focus of research that sociology of knowledge has maintained since its birth, and it is also an indispensable vision and fulcrum for seeing the problems of knowledge [8]. Therefore, this paper chooses to adopt the sociology of knowledge perspective. In the first part, it takes historical time as a clue to examine how that knowledge about gender and education were generated and evolved in specific historical and social situations, what political, economic and cultural purposes they served, how they influenced the educational practices of the time, and to what extent they have shaped the conception of gender education today.

In the second part, the paper explores new possibilities for realizing gender equality education in cyberspace, starting from a critique of classical sociology of knowledge from a mediated perspective. The development of gender equality education in China has reached a relatively stable plateau, both in terms of conceptual thinking and policy practice. At present, neither traditional educational practices nor legal policies have brought about a real breakthrough in gender equality in China. So, at a time when there are few possibilities for change at the Top-Level Design, there is an urgent need to explore the new possibilities offered by the new technologies of the network era to understand the shift in the discourse of gender equality and the new dynamics therein in the new human environment created by technology [9]. But at the same time, the political and capitalist nature of cyberspace and the narrative crisis brought about by digital media technology itself cannot be ignored $[10,11]$. In the post-modern context, the various stages of media production, dissemination, and reception are dynamic games in which various forces struggle and negotiate.

Similarly, the gender equality discourse is also in a complex field of power struggle and semantic competition. For a marginal discourse like gender equality, or feminism, which is already at a disadvantage in the real world, its independence and autonomy in cyberspace are even more difficult to guarantee. But these questions do not deny the possibility of gender equality education. Perhaps the ultimate path may also return to the classical propositions of Western Marxism: how to combat human alienation, how to combat ideological discipline, and how to awaken a greater sense of autonomy in people.

\section{THE EVOLUTION OF GENDER EQUALITY EDUCATION}

From the establishment of patriarchal society to the late Qing Dynasty, China experienced a long period of conspicuous educational non-equality in which the educational differences between men and women were incorporated very explicitly into the educational system or official literature under the influence of the concept of gender differentiation, and women's educational opportunities were greatly suppressed [12]. In the late 19th century, with the introduction of Western thought and the awakening of the nation's awareness of equality, intellectuals began to reflect on women's status in China and positively advocated for women's education. Liang proposed that the root of China's weakness begins with women's failure to learn [13]. Chen criticized the fallacy that a woman's lack of talent is her virtue and advocated that those women should enter the academy, learn something, and put the burden of saving the country on their shoulders [13].

According to Mannheim's sociology of knowledge, the perception of intellectual bias or ideology within a group undergoes a process of diffusion from the mobile pioneers to the surrounding followers, with these initial mobile individuals, who have a more comprehensive and objective understanding of the social environment due to their mobility and migration experiences, becoming pioneers and trailblazers and adapting their views to the changing environment. In contrast, others rejected new ideas but gradually followed them as their environment changed [14]. In the late Qing dynasty, a period filled with unprecedented changes, these intellectuals acted as pioneers with experience in foreign countries. The mid to late 19th century coincided with the first wave of feminism, one of whose debates was the right of women to education and these ideas were undoubtedly very powerful for those Chinese intellectuals who had grown 
up in a relatively conservative environment, and this led them to recognize the backwardness of Chinese ideas and to give women' s education an important place in their reforms. However, while recognizing the progressiveness of their views, it is also important to note that this group of male intellectuals' advocacy of women's education was closely linked to a set of discourses of national renewal and was largely a reaction to the stimulus of defeat in the war, rather than to the freedom and liberation of individual women, and was clearly instrumentalist in nature [15]. Moreover, their promotion of female education was hardly aimed at achieving equality in education, and the educational expectations placed on women were completely different from men's s political, economic and military participation, but rather the exercise of socialized motherhood [16].

With the fall of the Qing dynasty and the establishment of the Republic of China, the reflection and criticism of traditional Chinese culture became more intense. However, in terms of education for both men and women, the old framework was still not broken through, and the educational ideas of virtuous wives and mothers from Japan and the United States had a greater influence in China. From the establishment of the Republic of China to around the May Fourth Movement, the government constantly emphasized women's education in domestic affairs. The curriculum mostly concentrated on gardening, sewing and drawing, while the courses on law, economics and foreign languages were constantly reduced and deleted. The sociology of knowledge argues that knowledge can be based on ideology or interests and that a curriculum, subject or discipline constructed from knowledge is itself a combination of knowledge, power and discipline [16]. Scheler advocates paying close attention to the laws and rhythms of the diffusion of knowledge from the top downwards, particularly the role of institutions that disseminate knowledge, such as schools and publishing houses, in this diffusion process [8]. The emphasis on women's links with the family in school education, through a series of directives by the Republican government, constituted a form of discipline for women, which was the limitation of gender equality education in this period.

The May Fourth Movement was an important turning point in the development of gender equality education. During this period, a group of enthusiastic and radical intellectuals widely absorbed the progressive ideas of Western liberal democracy, and the pursuit of gender equality became a hallmark of modernity. At the same time, the growth of the Communist Party also contributed to gender equality, for according to Marxism, "the degree of women's emancipation in any society is the natural measure of universal emancipation" [17]

After the founding of New China, the gender roles and division of labor between men and women changed dramatically, and the state constructed a gender discourse of men and women are the same. Institutional differences between men and women in education were broken down, and women's right to education was guaranteed. From the sociology of knowledge perspective, it is not the theory of ideas that determines the emergence of a theory of ideas but the social context outside of it [18]. China's economic and social context at the time was that China had just emerged from the war and was in urgent need of productivity recovery. Socialist construction requires a large workforce, which in turn requires women to be educated, enter male occupations, and even become masculine to promote large-scale economic development. The guarantee of job opportunities for women under the planned economy contributed to the development of female education. This also explains why, after a socialist market economy and women replaced the planned economy had to compete in the market like men, many women returned to the family, reinforcing traditional female roles and indirectly influencing women's desire to pursue higher education [16].

Around the turn of the 21 st century, China entered an intensive policy, legal and institutional development to promote gender equality. State action to promote gender equality in education is strong, and gender equality of opportunity is gradually being achieved at all stages of education. However, there is still some way to go from legal equality to de facto equality and from equality of opportunity to equality of outcome [19]. Sociological research has shown that a mature idea is characterized by the resilience and the ability to sustain the reflection of its sedimentary energy. The long history of gender inequality in education has, through its uninterrupted social effects, ingrained sexist perceptions in the minds of people at all levels of society, resulting in gender stereotypes that are embedded in the explicitly genderequal education system and lead to the production of gender inequalities in the educational microcosm. These may be referred to as non-institutional sexism [20]. And they may be manifested in the higher expectations of teachers for men in the teaching and learning process and in the stereotypical portrayal of male and female roles in educational materials, which place women in a position of otherness in education as silent, passive learners. Foucault reveals how people's ways of thinking and behaving serve to dominate themselves, how they regulate themselves by producing truths, and how women's inferiority is not the result of male oppression but her self-regulation, self-rule and self-conformity [21]. And it is precisely in China that many teachers and parents conform to a gender-biased, female-unfriendly discourse and subliminally influence their students, many of whom are shaped in a way that caters to the expectations of society, which is the most important issue to focus on and change in Chinese education today. 


\section{MEDIA BIAS IN CYBERSPACE}

It can be seen that the discourse and practice of gender equality education in China has a clear group and social bias in its evolution. But in today's networked, platformbased society, media bias, which was somewhat neglected in classical sociology of knowledge, has become an extremely important variable in its own right. That is to say, in Mannheim's sociology of knowledge paradigm, influenced by the judgment of the time that technology is objective, he considered mass communication media such as newspapers and radio as mere socially biased carriers of mediate knowledge while ignoring a further bias of media [13]. But as Marshall McLuhan put it, any technology will gradually create a new human environment [9]. Therefore, although the technological myths of cyberspace have been dispelled in today's cyber age, cyberspace still has a certain heterogeneity compared to the real world. So now that gender equality education in China has become very stable and consistent at the political and policy levels, the new media may be one of the key drivers of narrowing the gap between upper-level ideology and the concrete practices of life.

From the affirmative action of ethnic minorities such as Black Lives Matter to the Metoo in the fourth wave of feminist movements, whether these movements eventually succeeded in some way or reverted to quietness, they were all, to a greater or lesser extent, informed by new media, especially social media [11]. The flatness, accessibility, relative anonymity and weak politicization of cyberspace have given greater discursive space to gender equality discourse, which is sensitive and marginalized in the real world, thus making the exchange of views in the public sphere possible again. Such a discursive space not only allows for a relatively free exchange of views but also empowers women, the Other in the real public sphere, to express themselves more freely and authentically. As Beryl Fletcher explains, the internet is a quiet place for me as a woman, precisely because I am physically absent, I can say and do what I like and no one sees my age, flaws, and vulnerability [22]. This leads to a growing interest in gender issues in cyberspace and the creation of a pattern of multiple exchanges of opinions, making it possible to generate new knowledge. But by its very nature, this plurality of opinion is still loose and antagonistic. The bias of the groups and social situations behind it prevents it from flowing freely across regions and classes, making it difficult for new knowledge to achieve its educational function. This, in turn, requires a higher level of coordination, thus introducing the concept of Gramsci's Organic Intellectuals [23].

In contrast to the class of intellectuals who, according to Mannheim, were responsible for the enlightenment and edification of the general public by correcting the bias of self-knowledge and enhancing the capacity for self-knowledge, organic intellectuals appeared to be more de-classed and de-elite [14]. Unlike traditional intellectuals, organic intellectuals in Gramsci's discourse are no longer the moniker of the cultural elite but point to a much larger number of the public. Its organic nature is reflected both in the de-elitist station and enlargement of the intelligence community and its close relationship with the public and society. Organic intellectuals fulfill their social integration and cultural dissemination functions through organic contact with the public [24]. The popularization and education of gender equality should not be elitist but rather a general education that is widely accessible. Naturally, organic intellectuals should take on the responsibility of enlightening and educating in this regard. At the same time, as mentioned earlier, cyberspace also provides organic intellectuals with adequate space for discourse. From the existing relevant practices, women have progressed in constructing their subjectivity and space in cyberspace. For example, with the new technological revolution and the new wave of feminism, Chinese women bloggers have proliferated, including feminist and women's culture promoters who are responsible for popularizing knowledge, as well as humanities bloggers, fitness bloggers, beauty bloggers, and the slightly-fat dress bloggers that have emerged in recent years, all of whom are using their bodies and words to express their resistance to the traditional gender stereotypes of female discipline. Some of them who are more influential can be opinion leaders in public opinion on social issues related to gender equality or even cause social issues by themselves [25].

However, it is important to note that cyberspace is not disconnected from the real world. As the boundaries between cyberspace and real space become increasingly blurred, people are becoming aware of the absurdity of the cyber myth. Driven by both the logic of capital and politics, inequality and inequity still define the overall pattern of the internet as a technological vehicle, and the ubiquitous ideology shatters the myth of IT neutrality in the digital age [10]. This, in turn, leads the organic intellectuals who live in it to unconsciously use or cater to the patriarchal discourse that dominates the ideology. At the same time, the modernity dilemma that emerged at the beginning of the 20th century as the age of transition is still present in today's society, especially in the online community, and tends to become more pronounced. The looseness and irrationality of online communities and the centralization of ideological propaganda pose a great challenge to gender equality education and the rational discussion of related issues [14].

Furthermore, concerning media technology itself, Byung-Chul Han argues the phenomenon of speech presented in digital media platforms as a narrative scarcity and attributes it to the annihilation of historical time in the [26]. In other words, the technology of memory reproduction in electronic media dissolves people's memories of the past and their expectations of 
the future. As a result, the differences and gaps between the past, present and future are all lost in digital social media, and they are all subsumed under the empty name of the present time through the manipulation of digital technology [26]. This present character makes the discourse in the digital media non-discursive and narrative-free, and people's speech in it becomes self-talk under algorithmic instructions [11]. In this media context, it is extremely difficult to rewrite any form of gender narrative.

\section{CONCLUSION}

Over the past two centuries, China has made a breakthrough in gender equality in education, enabling people to achieve equality of access and rights. This has been closely linked to changes in China's socio-political situation, economic system and social culture, and the awakening and difficult search of intellectuals.

However, inequalities in the process and outcomes of education still exist in today's society and are difficult to bridge. When traditional gender ideas are on the rise, patriarchal domination has also become more entrenched and difficult to eradicate.

Therefore, a means of weakening politicization might be a solution path. The weakly political, decentralized nature of the ideal cyberspace offers a free market for ideas, thus making possible a daily life-oriented, universal path to gender equality education.

Although this ideal state is inevitably disturbed by the logic of capital and politics, organic intellectuals can take responsibility for promoting an orderly flow of ideas. Meanwhile, both organic intellectuals and the wider public should be wary of the alienation of people by technology and the assimilation brought about by capital and always maintain a sense of group consciousness to counter the inevitable ideological discipline.

\section{REFERENCES}

[1] Jing, S,L., \& Lu, Hong. (2006). Equality of educational opportunities in a feminist perspective. Educational Theory and Practice, 26(1), 6-9.

[2] Qiang, HY (2000). Gender differences and education. Shaanxi People's Education Press.

[3] Xu, L., \& Niu, Q.Q. (2018). "Teaching according to sex" Discernment. Journal of Guangxi Normal University (Philosophy and Social Science Edition), 53(5), 122-128.

[4] Jia, Y.Z. (2006). Assessment of gender equality and women 's development in China's education sector. Women 's Studies Series, 2.

[5] Shi, M. J., Yu, Z.Y., \& Huang, H. (2012). A study of gender awareness among early childhood teachers in Beijing. Journal of China Women's College, (2), 96-101.

[6] Zhang, Z.S., \& Chen, Q. (2013). The expansion of higher education and the gender equalization of higher education opportunities: An empirical analysis based on data from the China General Social Survey (CGSS2008). Sociological Research, (2), 173-196.

[7] Hu, M., \& Chen, J. (2020). The relevance of educational science and educational policy: a sociology of knowledge perspective. Studies in the philosophy of science and technology (2).

[8] Gao, S.H. (2005). Strategies for presenting curriculum knowledge from a sociology of knowledge perspective: An introduction. Journal of Educational Science, Hunan Normal University, 4(3), 10-15.

[9] McLuhan, M., \& MCLUHAN, M. A. (1994). Understanding media: The extensions of man. MIT press.

[10] Hong, Y. (2020). Internet governance and states in the post-American era. Chinese Journal of Journalism \& Communication (02), 6-27.

[11] Yu, L. (2021). The coconstruction of media technology, body and narrative: A preliminary exploration of feminist media research approaches in the digital media era. Global Journal of Media Studies (01), 126-144.

[12] Lee, G. (2017). An examination of the historical development of gender equality education in China. Education and Teaching Forum, (2), 45-46.

[13] Zheng, Y.F., \& Li, DY (2011). Liang Qichao 's ideas on women 's emancipation. Journal of Jishou University (Social Science Edition), 32(1), 152.

[14] Wang, J.P. (2021). The origin, collision and synthesis of knowledge - Mannheim's ideas on knowledge dissemination and its contribution. International Journalism (07), 80-98.

[15] Paul, \& Bailey. (2003). Modernizing conservatism in early twentieth-century China: Discourses and practices in women's education. Chinese Education: Research and Review, 4(1), 1-26.

[16] Zhou, S.L., \& Du, S.Z. (2008). Educational traditions and their transcendence in a gender perspective. Educational Research (10), 33-38.

[17] Lin, M.S. (2010). Gender equality education: A new perspective on ideological and political education in higher education. Journal of South China Normal University: Social Science Edition, (3), 147-150. 
[18] Lei, Y., \& Wu, D.C. (2014). On the production and evolution of educational knowledge forms - An analysis based on a sociology of knowledge perspective. Educational Theory and Practice, (1), 3-8.]

[19] Zheng X.R., Wu, X.W., \& Lin S.H. (2020). Women and education: Processes and reflections on gender equality in education in China. Journal of Shandong Women 's College.

[20] Zhang, M.S., \& Ma, WY (2003).Socializing gender equality: A long and difficult process. Women 's Studies Series, (1), 5-9.

[21] Li, YH (2005). Feminism (Vol. 2). Shandong People's Publishing House.

[22] Beryl Fletcher, "Cyberfiction: A Fictional Journey into Cyberspace", in Susan Hawthorne and Renate Klein, eds., CyberFeminism: Connectivity, Critique and Creativity, North Melbourne: Spinifex Press, 1999, p.342.

[23] Hoare, Q., Nowell-Smith, G., Hoare, Q., \& NowellSmith, G. (2005). Selections from Prison Notebooks. London: Lawrence \& Wishart.

[24] Gong, Y. (2005). Gramsci on the "organic nature" of intellectuals. Journal of Chengdu University (Social Sciences) (02),10-12. doi:CNKI:SUN:CDDB.0.2005-02-004.

[25] Yu, D. (2008). An Exploration of Feminism in Famous Chinese Women Bloggers (Master's thesis, Capital Normal University).

[26] Han, B. C. (2014). Duft der Zeit: ein philosophischer Essay zur Kunst des Verweilens. transcript Verlag. 